\title{
Um percurso sobre a história da doença e dos medos sociais
}

\section{An investigation of the history of diseases and social fears}

\author{
Vanessa Nolasco Ferreira \\ Doutoranda, Ciências da Saúde/Escola Nacional de \\ Saúde Pública Sérgio Arouca/Fiocruz. \\ vnolascoferreira@gmail.com
}

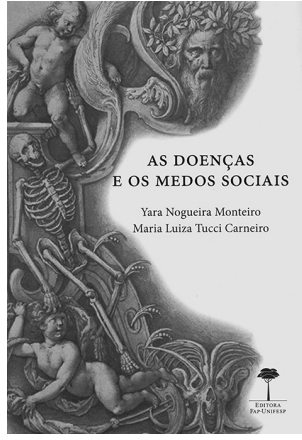

MONTEIRO, Yara Nogueira; CARNEIRO, Maria Luiza Tucci (Org.). A doença e os medos sociais. São Paulo: Fap-Unifesp. 2012. 440p.

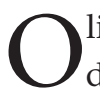
livro $A$ doença e os medos sociais tem como foco a "história das doenças, dos medos, da discriminação e de sua repercussão no meio social" (p.9). Seu objetivo é instigar o debate sobre os referidos temas, levando em conta os diferentes campos de conhecimento que podem ser exemplificados pela riquíssima e diversa formação dos autores de cada capítulo. A coletânea de textos faz com que o objetivo seja extrapolado, visto que a leitura de cada capítulo proporciona um panorama da história da doença no Brasil e suas correlações com o cenário internacional.

As organizadoras, Yara Monteiro Nogueira e Maria Luiza Tucci Carneiro, apresentam a doença como um estigma, no qual se entrecruzam mito e realidade, ressaltando a relação direta existente entre o adoecimento e a exclusão. Tal noção é aprofundada ao longo de 16 capítulos, divididos em quatro partes. Nessa divisão se encontra o maior problema do livro, pois não há um texto introdutório que elucide o motivo pelo qual a obra se encontra organizada dessa maneira. Além disso, não é citado o objetivo de cada uma das partes, não são apresentados os textos que compõem cada parte nem é estabelecida uma correlação entre os ricos assuntos tratados pelos autores. A falta de um texto de conclusão também agrava o problema apontado.

"O imaginário sobre a doença" constitui a primeira parte do livro, na qual são apresentados conceitos como medo, cultura da segurança versus a cultura do risco, imaginário e estigma. O medo é definido como sinônimo da insegurança que "assegura a conformidade social e cultural" (p.38) e espelha a possibilidade de morte eminente. Dessa forma, a cultura ocidental apropria-se do medo para produção de normas e regras sociais devido a sua capacidade de assumir diferentes feições e formas de existência. O medo aparecerá, por exemplo, nas artes e pode ser exemplificado pelo impacto da peste nas cidades de Florença e Viena e nas "posturas medievais sobre a lepra" (p.101). A partir da apreensão do medo pelas culturas, principalmente a ocidental, emergem a cultura de segurança e a cultura do risco, sendo a primeira a que legitima ciência e tecnologia como os saberes determinantes e preponderantes, enquanto a segunda enfatiza a noção de risco como ideia de advertência que contém força em si mesma. 
Os conceitos de estigma e imaginário aparecem imbricados e são muito bem explicados a partir de exemplos como o da lepra, cuja cura, quando descoberta, não ocasionou a alteração das representações sociais sobre os portadores de hanseníase. Os mesmos ainda são vistos como aqueles que devem ser isolados porque portam uma doença altamente contagiosa. Tal exemplo comporta a estigmatização do doente - o leproso - e a ação do imaginário sobre a realidade, apontando que mesmo uma doença que pode ser curada traz grande carga de preconceitos. As artes também servem como ilustração; no quadro A virgem e o menino, a saúde e a boa aparência demonstram uma preocupação com essa realidade, assim como ocorre em outras pinturas renascentistas. No entanto, a arte, por intermédio de obras citadas no livro, também pode resumir o medo e o estigma, como ocorre nas pinturas que retratam a peste negra ou portadores de enfermidades. Os capítulos que compõem essa seção, portanto, constroem a concepção do imaginário da doença como uma construção social que tem como base o medo e, como consequência, estigmatiza os doentes.

A segunda parte da obra apresenta caráter mais específico ao tratar das "Doenças e medos na formação da sociedade brasileira" por meio de narrativas sobre diferentes enfermidades e variados pontos de vista sobre elas. O banzo, melancolia que atingia majoritariamente escravos, é abordado como doença que contribuiu para a construção da hipótese de um imaginário de que o Brasil teria sido erguido com tristeza, conforme apresenta Gilberto Freyre (2006) no livro Casa-grande e senzala.

Uma contribuição interessante da seção é o ponto de vista dos viajantes, como observadores privilegiados da natureza brasileira e, por conseguinte, da doença. Sua visão permite que o leitor tome contato com o imaginário da doença no Brasil desde os primórdios de sua construção. "Constatamos que a literatura dos viajantes é uma fonte importante para o estudo da história da saúde e das doenças dentro das novas perspectivas historiográficas que, ampliando seu campo de pesquisa, possibilitam entender toda trama que tece a existência humana" (p.144).

Ao longo dos capítulos que compõem essa parte do livro, o medo, base do imaginário da doença, aparece de forma bastante explícita, seja como correlato da descrição, do isolamento, excesso e indiferença nas narrativas sobre a gripe espanhola em São Paulo; ou como a imagem da Hospedaria Central na ilha das Flores como local de exclusão e de difusão do medo. É interessante notar que o medo que parece estar no passado é apontado em um campo da doença bastante presente na atualidade: o do tabaco, que muitas vezes não pode ser citado ou tem sua historicidade abafada com base em argumentos médicos que remetem à cultura do risco. Essa hegemonia do medo é tão paralisante que a discussão é considerada muitas vezes criminosa, perdendo-se, com isso, interessantes estudos sobre o modo como o brasileiro fuma.

Tais reflexões são capazes de mostrar ao leitor que a doença, no arcabouço do imaginário apresentado na primeira parte, é um campo caracterizado pelo sofrimento e pela consciência da experiência mórbida. Dessa forma, a "cultura fornece aos indivíduos os limites dentro dos quais se operam as interpretações relativas aos fenômenos corporais e, em particular, a doenças e seus sintomas" (p.215).

Os medos, que perpassam toda a coletânea, são retomados na terceira parte, que se dedica ao estudo de sua difusão, e o expoente que perpassa os três capítulos da seção é a eugenia, como o gatilho que reedita rupturas e permanências acerca das doenças e medos sociais. Ela 
está presente nas "Metáforas roubadas à doença: particularidades do discurso racista" (p.251) que tomou conta do Brasil na Era Vargas, quando os judeus eram conhecidos como "cancro social" (p.255) e, nas palavras da época, "proliferavam como parasitas", ou mesmo quando se acreditava que os estrangeiros poderiam ser abrasileirados - uma metáfora do "verniz social" (p.256).

Também é demonstrado que as ideias de uma raça superior e/ou melhorada apresentavamse como paradigma universal; o $13^{\circ}$ capítulo aponta como essas teorias estavam presentes nos EUA, na URSS e na Alemanha nazista por meio de sua produção cinematográfica. Esses ideais de perfeição são tratados como julgamentos morais e políticos que disseminavam o pânico de doenças não existentes e de medos sociais que fizeram nações tentar a destruição de outras nações ou culturas.

A quarta e última seção do livro se dedica à questão das fontes para a história das doenças. A apresentação do projeto "Guia dos arquivos das santas casas do Brasil, século XVI ao XX", cujo objetivo é compreender as fontes sobre história e doença "explorando o modo como esses fragmentos [de documentos] assumem significados da tessitura de relações mais amplas" no contexto da relação das santas casas com a doença e os medos sociais e a polarização desses medos na cultura brasileira (p.337), busca sensibilizar o público - além de historiadores, arquivistas e biblioteconomistas - para a necessidade de realizar a preservação documental como responsabilidade de todos, por se tratar de um processo contínuo que contém mais do que memórias, mas o caráter identitário das doenças e medos sociais.

Outra vertente contemplada é a salvaguarda de documentos por uma instituição. Nesse contexto, é apresentado o Departamento de Arquivo e Documentação da Casa de Oswaldo Cruz, cujo objetivo é "reunir, preservar e dar acesso aos registros relevantes sobre a trajetória das Ciências Biomédicas e da Saúde Pública, bem como atuar como centro de referência e informação nessas áreas" (p.353). Vale ressaltar que a autora do capítulo destaca o projeto "Memória e história da hanseníase no Brasil através de seus depoentes (1960-2000)" como um exemplo do uso da história oral como forma de demonstrar a singularidade a partir da abrangência de aspectos tratados nos depoimentos.

O livro é encerrado com a apresentação da Rede Brasileira de História e Patrimônio Cultural da Saúde ressaltando que ela pode atuar como um dos braços da participação social na saúde, prevista na Constituição de 1988, e salvaguardar o que se refere à identidade, à memória e à ação da sociedade brasileira, em especial do Ministério da Saúde. Além disso, nesse último capítulo está contida a estrutura da Coordenação Geral de Documentação e Informação da Subsecretaria de Assuntos Administrativos da Secretaria Executiva do Ministério da Saúde e das instituições representadas na Rede, sendo um guia bastante rico para os que iniciam seus estudos sobre o tema.

É de suma importância reiterar que o objetivo de instigar o debate sobre a história da doença, sua correlação com os medos sociais e a repercussão no meio social, e a forma pela qual esse processo se dá tanto na cultura ocidental quanto, mais especificamente, no Brasil, é cumprido com excelência. Ainda há muito espaço para estudos sobre esse tema, e novos debates só têm a contribuir com o campo.

Recomendo o livro para os que estão iniciando tanto graduações em ciências da saúde quanto em ciências humanas devido à riqueza na ilustração da história das doenças e suas 
representações sociais com foco no contexto brasileiro. Aos que já estão na área há mais tempo a leitura pode incentivar novas ideias e promover debates sobre esse tema ainda pouco explorado.

\section{REFERÊNCIA}

FREYRE, Gilberto.

Casa-grande e senzala. São Paulo: Global. 2006.

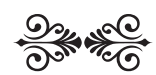

